\title{
EFEKTIVITAS PROGRAM PERHUTANAN SOSIAL DALAM BENTUK HUTAN KEMASYARAKATAN (HKM) DI DESA TANJUNG ALAM KABUPATEN KEPAHIANG PROVINSI BENGKULU
}

\author{
Yopita Sari $^{1)}$, Gunggung Senoaji ${ }^{2)}$, Hery Suhartoyo ${ }^{2)}$ \\ ${ }^{1)}$ Program Pascasarjana Pengelolaan Sumber Daya Alam dan Lingkungan, Fakultas \\ Pertanian, Universitas Bengkulu \\ 1) Dinas Lingkungan Hidup dan Kehutanan Provinsi Bengkulu \\ ${ }^{2)}$ Jurusan Kehutanan Fakultas Pertanian Universitas Bengkulu
}

\begin{abstract}
ABSTRAK
Program hutan kemasyarakatan $(\mathrm{HKm})$ adalah salah satu program yang dilaksanakan oleh pemerintah untuk mengatasi permasalahan kerusakan hutan dan perambahan kawasan hutan. Penelitian ini bertujuan untuk mengetahui Efektivitas Program Hutan Kemasyarakatan (HKm) dalam menjaga kelestarian kawasan hutan dan meningkatkan kesejahteraan masyarakat di sekitar kawasan hutan. Penelitian menggunakan metode observasi untuk mengetahui jenis tanaman, stratifikasi tajuk dan pola tanam, wawancara dan analisis good services ratio (GSR) untuk karakteristik sosial ekonomi masyarakat, untuk laju perubahan tutupan lahan menggunakan analisis spasial (Sistem Informasi Geografis). Hasil penelitian menunjukan bahwa Program Hutan Kemasyarakatan $(\mathrm{HKm})$ di Desa Tanjung Alam Kabupaten Kepahiang berjalan efektif dalam hal melestarikan kawasan hutan, hal ini ditunjukan dengan perubahan kondisi tutupan lahannya. Pada tahun 2000 kebun campuran 121,530 ha dan lahan pertanian 43,470 ha, pada tahun 2010 terlihat bahwa terjadi peningkatan penutupan lahan dalam kurun waktu 10 tahun terakhir, penggunaan lahan untuk lahan pertanian cenderung berkurang yaitu 18,056 Ha, dan kebun campuran meningkat menjadi 146,944 Ha. Lahan didominasi oleh kebun campuran dimana pohon-pohonnya rapat dengan kanopi menutupi areal. Pengamatan pada tahun 2017, untuk kebun campuran sedikit berkurang menjadi 141,460 ha, sementara lahan pertanian bertambah menjadi 23,540. Hutan Kemasyarakatan $(\mathrm{HKm})$ Desa Tanjung Alam Kabupaten Kepahiang termasuk dalam stratifikasi tajuk dengan 4 stratum yaitu stratum A, stratum B, stratum C dan stratum D. Hutan kemasyarakatan $(\mathrm{HKm})$ memberikan kotribusi besar dalam pendapatan peserta yaitu sebesar 93\% dengan rata-rata penghasilan peserta sebesar Rp 28.758.829,-- per tahun. Artinya peserta sangat bergantung terhadap keberadaan Hutan Kemasyarakatan (HKm) sebagai sumber pendapatan mereka. Sebagian besar peserta hutan kemasyarakatan Desa Tanjung Alam Kabupaten Kepahiang masih tergolong kurang sejahtera yaitu 24 responden dari 41 responden penelitian, 13 responden tergolong sejahtera dan 4 responden tergolong lebih sejahtera.
\end{abstract}

Kata Kunci : hutan lindung, hutan kemasyarakatan, kesejahteraan peserta HKm

\section{PENDAHULUAN}

Merujuk pada definisi yang
tertuang dalam UU No 4 tahun 2009
tentang Pertambangan Mineral dan
Batubara, pascatambang diartikan sebagai
kegiatan setelah akhir sebagian atau

seluruh kegiatan usaha pertambangan untuk memulihkan fungsi lingkungan dan fungsi sosial. Untuk mewujudkan pembangunan berkelanjutan, kegiatan usaha pertambangan harus dilaksanakan dengan memperhatikan prinsip lingkungan hidup, transparansi dan partisipasi 
masyarakat. Prinsip pengelolaan lingkungan hidup meliputi perlindungan terhadap kualitas air permukaan, air tanah, air laut, dan udara sesuai dengan standar baku mutu lingkungan hidup dan ketentuan peraturan perundang-undangan.

Kerusakan Hutan di Provinsi Bengkulu menurut data rekapitulasi kerusakan kawasan hutan Provinsi Bengkulu tahun 2018 Dinas Lingkungan Hidup dan Kehutanan mencapai \pm 19.027 ha, yang sebagian besar terjadi pada kawasan hutan lindung bukit daun yaitu sebesar \pm 6.161 ha. Besarnya kerusakan hutan yang terjadi diakibatkan oleh kegiatan perambahan hutan dan illegal logging yang tersebar di sembilan Kabupaten (DLHK, 2018). Banyaknya kawasan hutan yang diahlifungsikan oleh masyarakat menjadi lahan pertanian dan perkebunan mengakibatkan fungsi perlindungan dan keseimbangan lingkungan menjadi terganggu.

Faktor penentu yang menyebabkan rusaknnya hutan, khususnya di negara agraris adalah pertambahan penduduk. Pertambahan penduduk akan menambah rasio kepemilikan lahan atau luas lahan garapan (Simon, 2001 dalam Senoaji, 2010). Di lain pihak lahan pertanian sebagai penghasil pangan luasannya terbatas, sehingga alternatif utama untuk pemenuhan kebutuhan pangan adalah mengkonversi lahan hutan menjadi lahan pertanian. Selain itu, lahan hutan umumnya memiliki tingkat kesuburan tanah yang tinggi (Simon, 2003 dalam Senoaji, 2009).

Adanya tingkat deforestasi yang cukup tinggi dan kemiskinan yang mencengkeram masyarakat di dalam dan sekitar hutan membuat berbagai pihak termasuk Kementrian Kehutanan mencoba mendorong program Pemberdayaan Masyarakat atau Program Pengelolaan Hutan Berbasis Masyarakat (PHBM) (Rahmina, 2012). Kementerian Kehutanan mendorong pengembangan program PHBM melalui Hutan Kemasyarakatan (HKm), Hutan Desa (HD) dan kemitraan dengan Hutan Rakyat (HR), HKm dan HD yang dapat dikembangkan pada hutan lindung dan hutan produksi yang belum dibebani hak dan diperuntukkan bagi masyarakat yang punya ketergantungan dengan hutan.

Provinsi Bengkulu merupakan salah satu Provinsi yang terlibat dalam program tersebut. Berdasarkan Peta Indikatif Areal Perhutanan Sosial (PIAPS) pada wilayah KPHL Unit III Bukit Daun terdapat 29.048 Ha kawasan hutan yang dicanangkan untuk perhutanan sosial. PIAPS tersebut merupakan instrumen yang disiapkan untuk memberikan arahan kawasan hutan yang dapat dikelola oleh masyarakat dibawah skema Perhutanan Sosial, yakni pengelolaan Hutan Desa, Hutan Kemasyarakatan, Hutan Tanaman Rakyat, Kemitraan dan Hutan Hak (Fahrudin, 2017).

Program Perhutanan Sosial dalam bentuk Hutan Kemasyarakatan (HKm), sudah lebih dulu berjalan di Desa Tanjung Alam Kabupaten Kepahiang sejak tahun 2009, melalui Surat Keputusan Bupati Kepahiang Nomor : 470 Tahun 2009 hingga sekarang, dan termasuk dalam Kawasan Hutan Lindung Bukit Daun. Program ini dilaksanakan oleh pemerintah untuk mengatasi permasalahan kerusakan hutan dan perambahan kawasan hutan. Program hutan kemasyarakatan menurut pemerintah dapat menjadi solusi dalam merehabilitasi kawasan hutan yang telah rusak dan mampu menjadi solusi dalam meningkatkan kesejahteraan masyarakat yang sangat menggantungkan hidupnya terhadap keberadaan hutan, dengan kata lain jika perambah atau masyarakat di sekitar kawasan hutan memiliki kehidupan yang lebih sejahtera, maka kerusakan hutan akibat dari perambahan dapat berkurang.

Untuk melihat apakah hutan kemasyarakatan mampu menjadi solusi dalam mengatasi permasalahan kerusakan hutan dan perambah kawasan hutan, maka penting untuk melakukan penelitian mengenai Efektivitas Pelaksanaan 
Program Perhutanan Sosial dalam Bentuk Hutan Kemasyarakatan (HKm) di Desa Tanjung Alam Kabupaten Kepahiang. Parameter yang dapat menggambarkan tingkat kelestarian hutan, dan kesejahteraan masyarakat tersebut yaitu berupa kondisi tutupan lahan, komposisi jenis tanaman penyusun, struktur vegetasi dan karakteristik sosial ekonomi masyarakat.

\section{Tujuan Penelitian}

1. Mengetahui efektivitas program hutan kemasyarakatan (HKm) di Desa Tanjung Alam Kabupaten Kepahiang Provinsi Bengkulu dalam melestarikan kawasan hutan.

2. Mengetahui karakteristik sosial ekonomi peserta hutan kemasyarakatan (HKm) di Desa Tanjung Alam Kabupaten Kepahiang Provinsi Bengkulu.

\section{Batasan Masalah}

Adapun batasan masalah dalam penelitian ini adalah mengetahui kondisi Tutupan Lahan, Jenis Tanaman Penyusun, Struktur Vegetasi, dan Sosial Ekonomi Masyarakat di Desa Tanjung Alam Kabupaten Kepahiang Provinsi Bengkulu.

\section{METODE PENELITIAN}

\section{Lokasi Penelitian}

Penelitian ini dilakukan di Kawasan Hutan Kemasyarakatan di Desa Tanjung Alam Kabupaten Kepahiang.

\section{Alat dan Bahan}

Alat dan bahan yang digunakan adalah peta lokasi, kuesioner, kamera, GPS, spidol, alat tulis, $\mathrm{pH}$ meter, meteran, plastik, ring sampel tanah, citra satelit (citra lansat), Shp, ArcGIS dan tanaman di lokasi Hutan Kemasyaraaktan (HKm) Desa Tanjung Alam Kabupaten Kepahiang.

\section{Metode Pengumpulan Data}

Data dalam penelitian ini berupa data ekologi dan data sosial ekonomi masyarakat. Data ekologi dikumpul menggunakan metode mapping, survey dan observasi sedangkan untuk data sosial ekonomi dikumpul menggunakan metode survey dan wawancara (Hasan, 2008). Adapun data yang diambil dalam penelitian ini meliputi:

1. Data primer, dimana data langsung diperoleh dari wawancara kepada masyarakat dengan berpedoman kepada kuesioner. kuesioner diisi berdasar catatan lapangan. Informasi di dalam kuesioner mencakup hal-hal di bawah ini:

- Data ekologi meliputi tutupan lahan, startifikasi tajuk, jenis tanaman, tinggi tanaman, diameter tanaman, pola tanam dan kesuburan tanah.

- Data sosial ekomoni masyarakat, meliputi, mata pencaharian peserta HKm (pokok dan tambahan), luas kepemilikan lahan, pengeluaran rumah tangga, pendapat rumah tangga,

2. Data sekunder yaitu data yang dikumpulkan dari literatur dan instansi yang berhubungan dengan penelitian ini.

\section{Teknik Pengambilan Sampel}

Pengambilan sampel menggunakan Teknik Simpel Random Sampling yaitu pengembilan sampel anggota populasi secara acak tanpa memperhatikan strata (tingkatan) dalam anggota populasi tersebut, karena anggota populasi merupakan anggota populasi yang homogen (sejenis). Menurut Arikunto (2006) bahwa penelitian sosial besarnya sampel tergantung dari jumlah populasi yang ada. Jika jumlah populasi kurang dari 100 maka sebaiknya sampel diambil seluruhnya dan jika populasi lebih dari 100 maka sampel diambil antara $10-15 \%$ atau $20-25 \%$ atau lebih. 
Tabel 1. Nama-Nama Kelompok Tani Hutan Masyarakatan (HKm)

\begin{tabular}{clccc}
\hline No & $\begin{array}{c}\text { Nama Kelompok } \\
\text { Tani }\end{array}$ & $\begin{array}{c}\text { Luas Garapan } \\
(\mathrm{Ha})\end{array}$ & $\begin{array}{c}\text { Jumlah Anggota } \\
(\mathrm{KK})\end{array}$ & $\begin{array}{c}\text { Jumlah responden } \\
(\text { Orang }(40 \%))\end{array}$ \\
\hline 1 & Penantian & 30 & 16 & 7 \\
2 & Bangun Alam & 42 & 26 & 11 \\
3 & Sumber Usaha & 35 & 23 & 7 \\
4 & Lestari Kembali & 16 & 11 & 8 \\
5 & Sinar Sari & 42 & 25 & 8 \\
\hline & & 165 & 101 & 41 \\
\hline
\end{tabular}

\section{Analisis Data}

\section{Analisis Kondisi Lahan Hutan \\ Kemasyarakatan}

\section{- Perubahan Tutupan Lahan}

Perubahan tutupan lahan di analisis dengan menggunakan sistem informasi geografis dan pemanfaatan penginderaan jauh yaitu pemanfaatan citra satelit yang pada penelitian ini berupa citra Landsat 5 tahun 2000 dan 2010, Citra Sentinel S2A tahun 2017, Peta Kawasan Hutan Provinsi Bengkulu dan peta PAK HKm Desa Tanjung Alam Kabupaten Kepahiang. Sumber data tersebut akan diolah menggunakan ArcGIS dengan perbandingan per 10 tahun dan per 7 tahun.

\section{- Jenis Tanaman dan Pola} Tanam

Jenis tanaman dan pola tanam diketahui dari hasil wawancara kepada responden dan RKU Kelompok Tani Hutan Kemasyarakatan kemudian data yang didapat disesuaikan dengan data dari hasil observasi secara langsung ke lahan responden peserta hutan kemasyarakatan (HKm).

\section{Analisis Sosial Ekonomi Peserta Hutan Kemasyarakatan (HKm)}

- Nilai Ekonomi Produk HKm

Data diperoleh dari hasil pengamatan di lapangan melalui wawancara dan kuisioner kemudian dianalis secara kuantatif. Menurut Affandi dan Patanana (2002) dalam Zega (2013) nilai produk $\mathrm{HKm}$ untuk setiap jenis pertahun yang diperoleh masyarakat dapat dihitung dengan cara sebagai berikut :

a. Harga barang hasil hutan (manfaat tangible) yang diperoleh dengan pendekatan harga pasar (jika sudah dikenal harga pasarnya), penilaian dilakukan dengan nilai pasar atau nilai yang berlaku dipasar.

b. Nilai rata-rata jumlah barang yang diambil dapat dihitung dengan rumus :

$$
x=\frac{x i+x i i+\cdots+x n}{n}
$$

$\mathrm{X}=$ Rata-rata jumlah barang yang diambil (kg)

$\mathrm{xi}=$ Jumlah barang yang diambil responden $(\mathrm{kg})$

$\mathrm{n}=$ Jumlah pengambil per jenis tanaman

c. Total pengambilan per unit barang pertahun dapat dihitung dengan rumus sebagai berikut :

$$
\mathrm{TP}=\mathrm{RJ} X \mathrm{FP} \mathrm{X} \mathrm{JP}
$$

Keterangan :

$\mathrm{TP}=$ Total pengambilan

Pertahun (kg)

RJ = Rata-rata jumlah yang

Diambil (kg)

FP = Frekuensi pengambilan

JP = Jumlah pengambil

d. Nilai ekonomi produk $\mathrm{HKm}$ per jenis barang pertahun dapat dihitung dengan rumus : 
$\mathrm{NH}=\mathrm{TP} \times \mathrm{HH}$

Keterangan :

$\mathrm{NH}=$ Nilai produk HKm per jenis

$\mathrm{TP}=$ Total pengambilan (unit/tahun)

$\mathrm{HH}=$ Harga produk HKm $(\mathrm{Rp})$

e. Persentase nilai ekonomi dapat dihitung dengan dengan rumus :

$$
\% N E=\frac{N E i}{\sum N E} X 100 \%
$$

Keterangan :

$\% \mathrm{NE}=$ Persentase nilai ekonomi

$\mathrm{NEi}=$ Nilai ekonomi HKm per jenis

$\mathrm{NE}=$ Jumlah total nilai ekonomi dari seluruh produk HKm

f. Pendapatan dari $\mathrm{HKm}$, dari luar $\mathrm{HKm}$ dan pendapatan total dapat dihitung dengan cara sebagai berikut :

Pendapatan dari $\mathrm{HKm}=$ Jumlah nilai ekonomi dari seluruh jenis produk HKm

Pendapapatan luar $\mathrm{HKm}=$ Pendapatan total di luar HKm

Pendapatan total $=$ Jumlah pendapatan dari dan di luar

Tingkat kontribusi dapat dihitung dengan rumus :

Kontribusi

$=\frac{\text { Pendapatan dari } \mathrm{HKm}}{\text { Pendapatan total }} \times 100 \%$

\section{Analisis Kesejahteraan Peserta}

Analisis Kesejahteraan Peserta yaitu dengan menggunakan metode analisis
Good Services Ratio (GSR), tingkat pendapatan rumah tangga dan membandingkan pengeluaran konsumsi pangan (kebutuhan primer) dengan pengeluaran konsumsi di luar kebutuhan pangan (kebutuhan sekunder). Nilai GSR diperoleh dari suatu perbandingan antara jumlah pengeluaran untuk konsumsi bahan pangan dan konsumsi jasa dan pelayanan. (Fauzan, 2017). Adapun rumus yang bisa digunakan untuk menghitung nilai indek Good Service Ratio adalah :

$$
\text { GSR }=C_{p} / C_{j p} \quad(\text { Fajar, 2002). }
$$

Dimana :

$\mathrm{C}_{\mathrm{p}}=$ Besarnya nilai konsumsi barangbarang (goods) kebutuhan pokok, berupa pangan, sandang dan papan.

$\mathrm{C}_{\mathrm{jp}}=$ Besarnya nilai konsumsi jasa (services), baik berupa pendidikan, kesehatan, komunikasi dan sebagainya.

GSR $=>1$, artinya ekonomi rumah tangga kurang sejahtera

GSR $=1$, artinya ekonomi rumah tangga sejahtera

GSR $=<1$, artinya ekonomi rumah tangga lebih sejahtera

\section{HASIL DAN PEMBAHASAN}

Kondisi Lahan Hutan Kemasyarakatan - Kondisi Tutupan Vegetasi Hutan Kemasyarakatan Tahun 2000, 2010 dan 2017

Terjadi perubahan tutupan lahan di Hutan Kemasyarakatan (HKm) Desa Tanjung Alam Kabupaten Kepahiang yang diasjikan pada peta dan Tabel 2. 



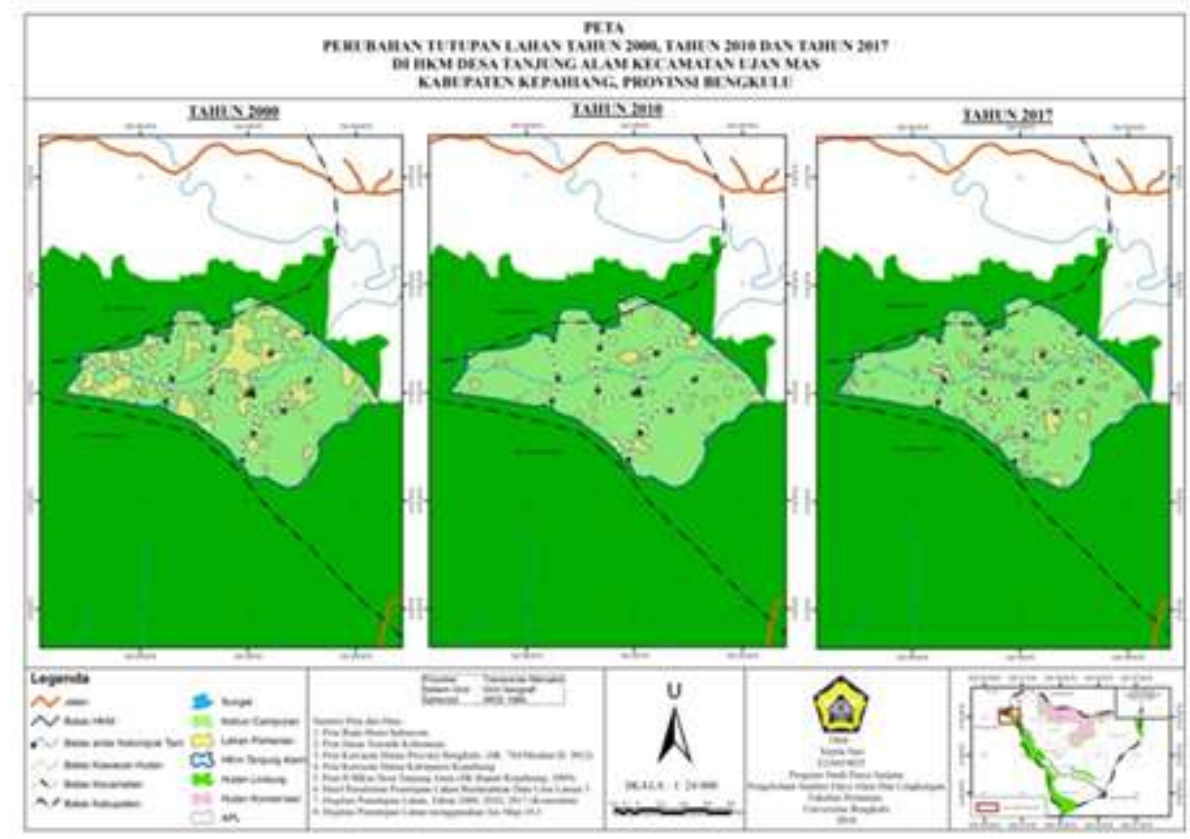

Gambar 1. Tutupan Vegetasi Hutan Kemasyarakatan Tahun 2000, 2010 dan 2017

Tabel 2. Perubahan Tutupan Lahan di Hutan Kemasyarakatan (HKm)

\begin{tabular}{|c|c|c|c|c|}
\hline No & Tutupan Lahan & $\begin{array}{c}\text { Tahun } 2000 \\
(\mathrm{Ha})\end{array}$ & $\begin{array}{c}\text { Tahun } 2010 \\
(\mathrm{Ha})\end{array}$ & $\begin{array}{c}\text { Tahun } 2017 \\
\text { (Ha) }\end{array}$ \\
\hline 1 & Kebun Campuran & 121,530 & 146,944 & 141,460 \\
\hline 2 & Lahan Pertanian & 43,470 & 18,056 & 23,540 \\
\hline & Jumlah & 165,000 & 165,000 & 165.000 \\
\hline
\end{tabular}

Pada data Tabel 2 terlihat bahwa terjadi perubahan tutupan lahan di Hutan Kemasyarakatan (HKm) Desa Tanjung Alam Kabupaten Kepahiang. Berdasarkan Badan Standarisasi Nasional Tahun 2010 tentang Klasifikasi Penutupan Lahan, klasifikasi jenis tutupalan lahan pada hutan kemasyarakatan Desa Tanjung Alam Kabupaten Kepahiang adalah termasuk pada kelas kebun campuran. Kebun campuran adalah lahan yang ditanami tanaman keras lebih dari satu jenis atau tidak seragam yang menghasilkan bunga, buah dan getah. Cara pengambilan hasilnya bukan dengan cara menebang pohon (BSN, 2010).

Pada tahun 2000 hutan kemasyarakatan di Desa Tanjung Alam
Kabupaten Kepahiang, sudah berbentuk kebun campuran dan lahan pertanian, bukan merupakan hutan primer dengan luas lahan yaitu $165 \mathrm{Ha}$, yang terbagi menjadi kebun campuran seluas 121,530 ha dan lahan pertanian seluas 43,470 ha. Lahan pertanian ini merupakan pemanfaatan lahan untuk jenis tanaman pertanian yang dikerjakan secara tetap dan insentif dengan bermacam-macam jenis tanaman secara bergantian antara tanaman palawija dengan tanaman semusim. Pada tahun 2010 terlihat bahwa terjadi peningkatan penutupan lahan dalam kurun waktu 10 tahun terakhir. Penggunaan lahan untuk lahan pertanian cenderung berkurang yaitu 18,056 Ha, dan kebun campuran meningkat menjadi 146,944 Ha. 
Lahan didominasi oleh kebun campuran dimana pohon-pohonnya rapat dengan kanopi menutupi areal. Pengamatan pada tahun 2017, untuk kebun campuran sedikit berkurang menjadi 141,460 ha, sementara lahan pertanian bertambah menjadi 23,540 ha. Tutupan vegetasi pada hutan kemasyarakatan di Desa Tanjung Alam Kabupaten Kepahiang berupa kebun campuran dengan pola agroforestry berbasis kopi. Terdapat pengaruh nyata dari terbentuknya hutan kemasyarakatan $(\mathrm{HKm})$, terhadap perubahan tutupan lahan pada pengelolaan kawasan Hutan Lindung Bukit Daun. Perubahan tutupan lahan hanya seluas 5,484 ha dalam kurun waktu 7 tahun terakhir, namun lahan hutan kemasyarakatan masih didominasi oleh kebun campuran seluas 141,460 ha.

Pada dasarnya hutan kemasyarakatan diperuntukan untuk membantu merehabilitasi kawasan hutan yang sudah dialihfungsikan untuk dapat kembali memiliki fungsi ekologi, dengan harapan seluruh lahan memiliki vegetasi tertutup, namun saat ini pada kasus hutan kemasyarakatan di Desa Tanjung Alam Kabupaten Kepahiang mengalami revolusi, dimana peserta juga memanfaatkan sedikit lahan mereka untuk difungsikan sebagai lahan pertanian yaitu penanaman jenis tanaman budidaya yang memerlukan ruang terbuka untuk dapat tumbuh dan memiliki hasil panen yang maksimal, seperti cabe, nanas, tomat, terong dan lain sebagainya seluas $\pm 100-$ $300 \mathrm{~m}^{2}$, atau secara keseluruhan seluas 23,540 h, walapun kecenderungan peserta lebih memanfaatkan kebun campuran.

\section{Jenis-jenis Tanaman dan Stratifikasi Tajuk di Lahan Peserta Hutan Kemasyarakatan}

Jenis-jenis tanaman yang di tanam oleh peserta Hutan Kemasyarakatan Desa Tanjung Alam adalah tanaman pertanian dan tanaman kehutanan yang disajikan pada Tabel 3.

Tabel 3. Jenis-jenis Tanaman di Lahan Peserta Hutan Kemasyarakatan (HKm)

\begin{tabular}{|c|c|c|c|c|}
\hline No & Jenis Tanaman & Nama Ilmiah & Diameter (cm) & Tinggi (m/cm) \\
\hline 1 & Kopi & Coffea arabica & $5,4-11$ & $1,5-2,0$ \\
\hline 2 & Kayu Res/Gamal & Gliricidia sepium & $20-37$ & $3,5-12$ \\
\hline 3 & Pinang & Areca catechu & $14-19$ & $2,0-15$ \\
\hline 4 & Jengkol & Archidendron pauciflorum & $28-32$ & $2,5-8,0$ \\
\hline 5 & Petai & Parkia speciosa & $23-47$ & $5,0-18$ \\
\hline 6 & Durian & Durio zibethinus & $11-58$ & $2,0-16$ \\
\hline 7 & Pala & Myristica fragrans & $14-23$ & $1,5-3,0$ \\
\hline 8 & Alpokat & Persea americana & $22-34$ & $4,0-8,5$ \\
\hline 9 & Karet & Hevea brasiliensis & $14-21$ & $3,0-7,0$ \\
\hline 10 & Suren & Toona sureni Merr & $25-44$ & $10-16$ \\
\hline 11 & Meranti & Shorea sp & $37-50$ & $8,0-20$ \\
\hline 12 & Sungkai & Peronema canescens & $31-47$ & $7,0-15$ \\
\hline 13 & Jati & Tectona grandis & $30-38$ & $7,0-15$ \\
\hline 14 & Kemiri & $\begin{array}{l}\text { Aleurites moluccana } \\
\text { (L.) Willd }\end{array}$ & $38-41$ & $10-15$ \\
\hline 15 & Jambu Bol & Syzygium malaccense & $39-45$ & $4,0-7,0$ \\
\hline 16 & Jambu Air & Syzygium aqueum & $27-29$ & $2,5-3,5$ \\
\hline 17 & Terong & Solanum melongena & - & $60-95$ \\
\hline 18 & Cabe & $\begin{array}{l}\text { Capsicum annuиm } \\
\text { 'Bird's Eye' }\end{array}$ & - & $75-95$ \\
\hline 19 & Bambu & Bambuseae & $14-19$ & $4,0-13$ \\
\hline 20 & Medang & Litsea spp & $31-48$ & $10-20$ \\
\hline 21 & Aren & Arenga pinnata & $50-65$ & $15-18$ \\
\hline 22 & Bambang Lanang & Michelia champaca & $20-41$ & $9,0-16$ \\
\hline 23 & Nangka & Artocarpus heterophyllus & $20-40$ & $3,0-6,5$ \\
\hline 24 & Kapuk & Ceiba pentandra & $37-95$ & $9,0-20$ \\
\hline 25 & Rambutan & Nephelium lappaceum & $29-43$ & $7,0-10$ \\
\hline
\end{tabular}




\begin{tabular}{lllcr}
\hline 26 & Rotan & Calameae & $2,8-4,4$ & $2,0-5,0$ \\
27 & Tomat & Solanum lycopersicum & - & $30-60$ \\
28 & Nanas & Ananas comosus & - & $45-60$ \\
\hline
\end{tabular}

Jenis-jenis tanaman yang di tanam oleh peserta Hutan Kemasyarakatan Desa Tanjung Alam adalah tanaman pertanian dan tanaman kehutanan. Terdapat \pm 28 jenis tanaman yang dimanfaatkan oleh responden peserta Hutan Kemasyarakatan (HKm) Desa Tanjung Alam yang terdiri dari 8 jenis tanaman pertanian, 11 jenis tanaman MPTS, 9 jenis tanaman kayu rimba. 28 jenis tanaman tersebut hasil yang dimanfaatkan berupa buah dan kayu. Sedangkan berdasarkan data jenis, diameter dan tinggi tanamannya dapat dilihat salah satu unsur struktur vegetasi berupa startifikasi tajuk pada lahan tersebut. Stratifikasi tajuk dapat digunakan untuk melihat pola pemanfaatan cahaya, serta dapat pula digunakan untuk melihat jenisjenis pohon dominan dan jenis-jenis pohon yang dapat tumbuh di bawah naungan (toleran) (Mulyasana, 2008). Menurut Indriyanto, 2006 bahwa stratifikasi tajuk dalam hutan hujan tropika dapat dibagi menjadi lima stratum berurutan dari atas ke bawah, yaitu stratum A, stratum B, stra- tum C dan stratum DPada Hutan Kemasyarakatan (HKm) Desa Tanjung Alam Kabupaten Kepahiang berdasarkan stratifikasi tajuk tersebut, memiliki 4 tingkatan stratum yang terdiri dari startum A merupakan jenis-jenis tanaman rimba dengan tinggi $\pm 15-20$ meter. Starum B merupakan jenis bambu dan jenis tanaman MPTS dengan tinggi \pm 7 - 14 meter, pada startum $\mathrm{C}$ yaitu tanaman pertanian komoditi dengan ketinggian $\pm 1,5$ - 6 meter. Startum D diisi oleh jenis tanaman penutup lantai hutan. Meyer, 1952 menjelaskan kondisi hutan semacam ini, akan menjamin kelestarian hutan di masa yang akan datang karena jumlah individu permudaan jauh lebih banyak dari pada jumlah individu pohon dewasa, dimana stok permudaan tersebut sangat penting untuk memelihara kemampuan regenerasi hutan. Vegetasi penutup tanah yang mempunyai struktur tajuk berlapis dapat menurunkan energi kinetik air hujan dan memperkecil diameter tetesan air hujan (Nurpilihan dkk, 2011).

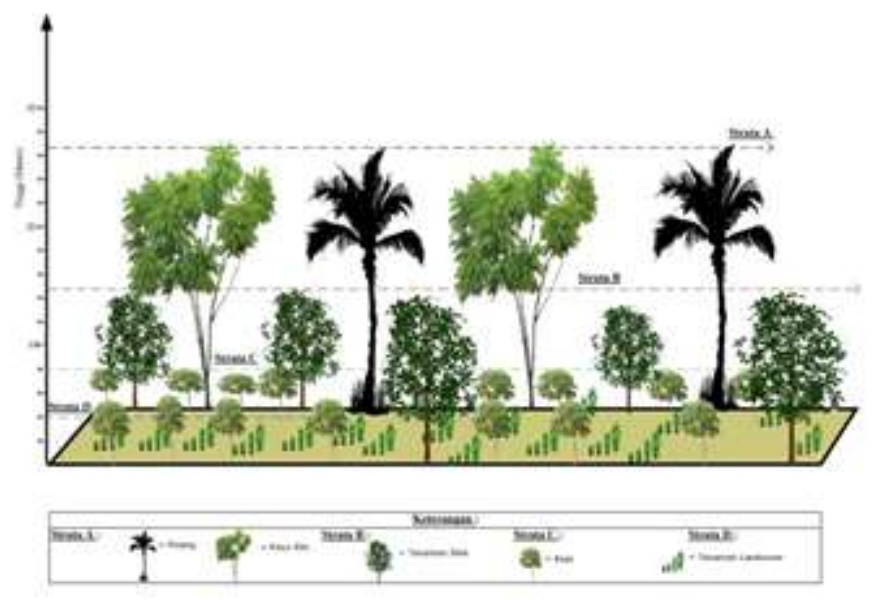

Gambar 1. Stratifikasi Tajuk HKm Desa Tanjung Alam

Pola Tanam di Lahan Hutan 
Hutan Kemasyarakatan (HKm) Desa Tanjung Alam Kabupaten Kepahiang memanfaatakan lahan dengan pola agroforestry. Pembeda setiap pola hanya pada tanaman pagar. Ada lahan dengan tanaman pagar penuh jarak tanam $3 \mathrm{~m} \times 3$ $\mathrm{m}$, lahan dengan tanaman pagar jarang yaitu hanya beberapa tanaman pagar sebagai batas antar lahan dan lahan tanpa tanaman pagar yaitu pada lahan yang berbatasan langsung dengan hutan alam. Masyarakat memanfaatkan ruang pada lahan dengan menanam tanaman sela secara sembarang seperti jenis-jenis tanaman MPTS secara langsung oleh peserta untuk kebutuhan sehari-hari. Untuk tanaman peneduh ditanam dengan jarak tanam $7 \mathrm{~m} \mathrm{x} 7 \mathrm{~m}$ dan tanaman pokok ditanam dengan jarak $3 \mathrm{~m}$ x $3 \mathrm{~m}$.

Selain tanaman kopi sebagai komoditi utama, tanaman sela jenis pala juga dimanfatakan untuk keperluan komersil namun pada saat penelitian, umur tanaman pala kebanyakan baru 3-4 tahun tanam, hanya beberapa yang berusi antara 5-6 tahun, sehingga baru sedikit saja yang sudah panen dan dapat di jual. Selain itu tanaman sela berupa pinang dimanfaatkan juga untuk kebutuhan komersil. Untuk jenis tanaman pertanian seperti cabe dan terong, ditanam pada lahan yang memang sudah dikosongan dan difungsikan untuk budidaya tanaman pertanian.

\section{Sosial Ekonomi Peserta Hutan Kemasyarakatan (HKm) Desa Tanjung Alam Kabupaten Kepahiang \\ - Nilai Ekonomi Produk HKm}

Tabel 4. Persentase Nilai Ekonomi Produk Hasil Hutan Kemasyarakatan (HKm)

\begin{tabular}{llcccccc}
\hline No & $\begin{array}{c}\text { Pnghsiln } \\
\text { dari HKm }\end{array}$ & $\begin{array}{c}\text { Jmlh } \\
\text { Kg/Th }\end{array}$ & $\begin{array}{c}\text { Jmlh } \\
\text { Pngmbl } \\
\text { (Org) }\end{array}$ & $\begin{array}{c}\text { Rata-rata } \\
\text { yg diambil } \\
\text { Kg/Th }\end{array}$ & $\begin{array}{c}\text { Harga } \\
\text { Rp/Kg }\end{array}$ & $\begin{array}{c}\text { NH } \\
(\mathrm{Rp})\end{array}$ & $\%$ NE \\
\hline 1 & Kopi & 47900 & 41 & 1168,29 & 20.000 & 23.365 .84 & 59,93 \\
2 & Pinang & 22104 & 39 & 566,77 & 8.000 & 4.534 .154 & 11,63 \\
3 & Pala & 756 & 10 & 75,60 & 80.000 & 6.048 .000 & 15,51 \\
4 & Cabe & 960 & 5 & 192 & 20.000 & 3.840 .000 & 9,85 \\
5 & Terong & 600 & 2 & 300 & 4.000 & 1.200 .000 & 3,08 \\
\hline \multicolumn{2}{r}{ TP } & & & 2302,66 & NE & 28.222 .24 & $100 \%$ \\
\hline
\end{tabular}

Ada 5 jenis tanaman yang dimanfaatkan oleh peserta Hutan Kemasyarakatan Desa Tanjung Alam Kabupaten Kepahiang untuk kebutuhan komersil yaitu kopi, pinang, pala, cabe dan terong. Nilai ekonomi pemanfaatan dari 5 jenis tanaman tersebut yaitu sebesar $\mathrm{Rp}$ 2302,66 -per tahun. Dapat diketahui bahwa besarnya pemanfaatan tiap jenis produk Hutan Kemasyarakatan dipengaruhi oleh jumlah barang yang diambil tiap responden dan frekuensi pengambilan.
Berdasarkan pendekatan nilai pasar dan nilai relatif per jenis tanaman maka didapatkan bahwa nilai produk agroforestry peserta Hutan Kemasyarakatan yang paling besar yaitu tanaman kopi $\mathrm{Rp}$ 23.365.854,- dengan persentase nilai ekonomi 59,93\%. Bachruni (1999) mengatakan nilai guna langsung merupakan nilai yang bersumber dari penggunaan secara langsung oleh masyarakat terhadap komoditas hasil hutan berupa flora dan fauna. 
Tabel 5. Pendapatan Responden dari Produk Hutan Kemasyarakatan (HKm)

\begin{tabular}{lccc}
\hline \multirow{2}{*}{ Kategori } & Jumlah & Penghasilan/KK/Tahun & Luas Lahan \\
\cline { 2 - 2 } & KK(Org) & $(\mathrm{Rp})$ & $(\mathrm{Ha})$ \\
Rendah & 11 & $\leq 20.000 .000$ & $1-1,5$ \\
Sedang & 20 & $21.000 .000-35.000 .000$ & $1-2$ \\
Tinggi & 10 & $\geq 36.000 .000$ & 2 \\
\hline
\end{tabular}

Tabel 6. Pendapatan Responden dari Luar Hutan Kemasyarakatan (Hkm)

\begin{tabular}{lcc}
\hline $\begin{array}{l}\text { Jenis Kegiatan di Luar Hutan } \\
\text { Kemasyarakatan }(\mathrm{HKm})\end{array}$ & $\begin{array}{c}\text { Jumlah } \\
\text { KK } \\
(\mathrm{Org})\end{array}$ & $\begin{array}{c}\text { Penghasilan/KK/Tahun } \\
(\mathrm{Rp})\end{array}$ \\
\hline Sawah & 6 & $5.000 .000-11.000 .000$ \\
Perangkat Desa & 1 & 14.400 .000 \\
Ojek & 1 & 3.600 .000 \\
Salon & 1 & 12.000 .000 \\
\hline
\end{tabular}

Tabel 7. Kontribusi Produk Hutan Kemasyarakatan (HKm)

\begin{tabular}{clcc}
\hline No & Penghasilan & $\begin{array}{c}\text { Total Penghasilan/Tahun } \\
(\mathrm{Rp})\end{array}$ & $\begin{array}{c}\text { Rata-Rata } \\
\text { Penghasilan/Tahun } \\
(\mathrm{Rp})\end{array}$ \\
\hline 1 & Pendapatan dari HKm & 1.179 .112 .000 & 28.758 .829 \\
2 & Pendapatan dari Luar HKm & 82.910 .000 & 2.236 .829 \\
3 & Pendapatan Total & 1.240 .022 .000 & 30.244 .439 \\
\hline \multicolumn{2}{c}{ Kontribusi } & $93 \%$ & $93 \%$ \\
\hline
\end{tabular}

Pada Tabel 5, Tabel 6 dan Tabel 7 diketahui bahwa Hutan Kemasyarakatan $(\mathrm{HKm})$ memberikan kotribusi besar dalam pendapatan peserta yaitu sebesar 93\% dengan rata-rata penghasilan peserta sebesar Rp 28.758.829,- per tahun. Artinya peserta sangat bergantung terhadap Hutan Kemasyarakatan sebagai sumber pendapatan mereka. Menurut Rahim (2007) bahwa semakin luas lahan (digarap/ditanami), semakin besar jumlah produksi yang dihasilkan oleh lahan tersebut.

Kondisi tegakan yang sudah tua berkisar antara 15 tahun ke atas, pengelolaan lahan dan tanaman yang kuran, modal usaha kurang yang kurang merupakan faktor mengapa peserta dengan penguasan lahan yang luas menghasilkan produk hasil hutan yang sedikit. Proses produksi bisa berjalan bila persyaratan yang dibutuhkan yaitu faktor produksi sudah terpenuhi. Faktor produksi terdiri dari empat komponen, yaitu tanah, modal, tenaga kerja, dan skill atau manejemen (pengelolaan). Dalam beberapa literatur, sebagian para ahli mencantumkan hanya tiga faktor produksi yaitu tanah, modal, dan tenaga kerja. Masing -masing faktor mempunyai fungsi yang berbeda dan saling terkait satu sama lain. Jika salah satu faktor tidak tersedia maka proses produksi atau usaha tani tidak akan berjalan, terutama ketiga faktor seperti tanah, modal dan tenaga kerja (Daniel, 2004)

\section{Tingkat Kesejahteraan Peserta Hutan Kemasyarakatan (Hkm) Desa Tanjung Alam}

Dari hasil penelitian dan analisis data tingkat kesejahteraan peserta Hutan Kemasyarakatan (HKm) Desa Tanjung Alam Kabupaten Kepahiang disajikan dalam Tabel 8 berikut ini : 
Tabel 8. Tingkat Kesejahteraan Peserta Hutan Kemasyarakatan (HKm)

\begin{tabular}{clc}
\hline No & Analisis GSR & Jumlah KK \\
\hline 1 & Kurang Sejahtera & 4 \\
2 & Sejahtera & 13 \\
3 & Lebih Sejahtera & 24 \\
\hline Jumlah & 41 \\
\hline
\end{tabular}

Analisis Good Services Ratio (GSR) menunjukan bahwa dari 41 responden terdapat 24 responden dengan kategori kurang sejahtera. Umumnya peserta dengan kategori kurang sejahtera lebih mengutamakan kebutuhan primer, mereka belum bertindak lebih menyisikan uang untuk kebutuhan pendidikan, kesehatan, fasilitas rumah ataupun rekreasi dan lain sebagainya. Pendidikan belum menjadi hal yang penting, rata-rata mereka menyekolahkan anak hanya sebatas SMA, dorongan terhadap anak akan pentingnya untuk mengecam pendidikan yang lebih tinggi pun masih sangat kurang.

Peserta Hutan Kemasyarakatan pada penelitian ini sebanyak 13 responden tergolong masyarakat dengan kategori sejahtera dan 4 responden tergolong lebih sejahtera. Peserta dengan kategori sejahtera dan lebih sejahtera pemikiran untuk memenuhi kebutuhan hidup sudah lebih modern, mereka sudah berfikir bahwa hasil usaha tidak hanya digunakan untuk memenuhi kebutuhan primer saja melainkan juga kebutuhan sekunder. Mereka sudah berfikir bahwa pendidikan yang tinggi, rekreasi, kesehatan, memenuhi kebutuan fasilitas rumah, membayar pajak dan lain sebagainya adalah hal yang penting. Ada usaha yang dilakukan oleh peserta dalam membagi uang hasil pendapatan untuk kebutuhan primer dan untuk kebutuhan sekunder.

\section{KESIMPULAN}

1. Program Hutan Kemasyarakatan (HKm) di Desa Tanjung Alam Kabupaten Kepahiang berjalan dengan efektif dalam hal melestarikan kawasan hutan, hal ini ditunjukan dengan perubahan kondisi tutupan lahannya. Pada tahun 2000 kebun campuran 121,530 ha dan lahan pertanian 43,470 ha, pada tahun 2010 penggunaan lahan untuk lahan pertanian cenderung berkurang yaitu 18,056 ha, dan kebun campuran meningkat menjadi 146,944 ha. Lahan didominasi oleh kebun campuran dimana pohon-pohonnya rapat dengan kanopi menutupi areal. Pengamatan pada tahun 2017, untuk kebun campuran sedikit berkurang menjadi 141,460 ha, sementara lahan pertanian bertambah menjadi 23,540 ha. Hutan Kemasyarakatan (HKm) Desa Tanjung Alam Kabupaten Kepahiang termasuk dalam klasifikasi tajuk dengan 4 stratum yaitu stratum A, stratum B, stratum C dan stratum D.

2. Hutan kemasyarakatan (HKm) memberikan kotribusi besar dalam pendapatan peserta yaitu sebesar 93\% dengan rata-rata penghasilan peserta sebesar Rp 28.758.829,-- per tahun. Artinya peserta sangat bergantung terhadap keberadaan Hutan Kemasyarakatan (HKm) sebagai sumber pendapatan mereka. Sebagian besar peserta hutan kemasyarakatan Desa Tanjung Alam Kabupaten Kepahiang masih tergolong kurang sejahtera yaitu 24 responden dari 41 responden penelitian, 13 responden tergolong sejahtera dan 4 responden tergolong lebih sejahtera.

\section{DAFTAR PUSTAKA}

Arikunto, S. 2006. Metodelogi penelitian. Bina Aksara. Yogyakarta 
Bachruni. 1999. Penilaian Sumber Daya Hutan dan Lingkungan. IPB. Bogor

BSN. 2010. Klasifikasi Penutup Lahan. Kementerian Lingkungan Hidup dan Kehutanan. Jakarta

Daniel, M. 2004. Pengantar Ekonomi pertanian. Jakarta: PT Bumi Aksara.

DLHK. 2018. Data Rekapitulasi Daerah Kerusakan Kawasan Hutan Provinsi Bengkulu Tahun 2018. Bengkulu

Fahrudin, A. 2017. Rencana Pengelolaan Hutan Jangka Panjang KPHL Unit III Bukit Daun Provinsi Bengkulu. Kementerian Lingkungan Hidup dan Kehutanan. Jakarta

Fajar, O. A. 2002. Efektivitas Program Hutan Kemasyarakatan Dalam Meningkatkan Kesejahteraan Masyarakat Melalui Redistribusi Lahan. Thesis. Institut Pertanian Bogor, Bogor (dipublikasikan)

Fauzan, M dan Akhmadi, H. 2017. Analisis Ekonomi Rumah Tangga Peternak Sapi Perah Pasca Erupsi Gunung Merapi Dalam Mendukung Penghidupan Berkelanjutan di Hunian Tetap Pagerjurang Kabupaten Sleman. Ekonomi Pertanian. Universitas Muhammadiyah Yogyakarta. Yogyakarta.

Hasan, I. M. 2008. Pokok-Pokok Materi Statistik 1 (Statistik Deskriptif). Bumi Aksara. Jakarta.
Indriyanto. 2006. Ekologi Hutan. Buku. Bumi Aksara. Jakarta. 210 p.

Meyer H., A, D Stevensonand. 1961. Forest Management 2nd Edition. New York. The Ronald Press Company

Nurpilihan, B., K. Amaru, E. Suryadi. 2011. Buku Ajar Teknik Pengawetan Tanah dan Air. Teknik dan Manajemen Industri Pertanian. FTIP. UNPAD.

Rahim, Abdul dan Diah Retno Dwi Hastuti. 2007. Ekonomika Pertanian (Pengantar, teori dan kasus). Penebar Swadaya. Jakarta.

Rahmina. 2012. Pilihan Skema Pengelolaan Hutan Berbasis Masyarakat dalam Mitigasi Perubahan Iklim. Forclime. Jakarta

Senoaji, G. 2010. Studi Kesesuaian Lahan Untu Penentuan Kawasan Lindung di Hutan Lindung Konak Kabuapaten Kepahiang Propinsi Bengkulu. Jurnal Ilmu Kehutanan 4 (1): 12-20

Senoaji, G. 2009. Kontribusi Hutan Lindung Terhadap Pendapatan Masyarakat Desa di Sekitarnya: Studi Kasusu di Desa Air Lanang Bengkulu. Jurnal Manusia dan Lingkungan 16(1): 12-22

Zega, S., B. Purwoko, A. Martial, T. 2013. Analisis Pengelolaan HKm dan Kontribusi terhadap Perekonomian Masyarakat. Jurnal Bidang Kehutanan 2 (2): 152-162 